


\title{
Cash Transfer Programs and Household Labor Supply*
}

\author{
Daniela Del Boca ${ }^{\dagger} \quad$ Chiara Pronzato ${ }^{\ddagger}$ Giuseppe Sorrenti ${ }^{\S}$
}

March 2020

\begin{abstract}
Employment helps reduce the risk of poverty. Through a randomized controlled trial, we evaluate the impact of a conditional cash transfer (CCT) program to low-income families with dependent children on household members' labor supply. Recipients are required to attend labor-market-oriented mentoring courses as a condition of the transfer. One year after admission to the program, fathers assigned to the CCT program are more likely to work (+14 percent) than fathers assigned to an unconditional cash transfer program or to a pure control group. No effect arises for mothers. Results seem to be explained by improved family networks and increased parental investments in activities that enhance labor market opportunities.
\end{abstract}

JEL Classification: I10, I20, J24, I31.

Keywords: conditional cash transfers, poverty, household labor supply, mentoring courses.

${ }^{*}$ We wish to thank seminar and conference audiences at San Diego, Munich, NYU, Keio, Hitotsubashi, University of Turin, and Collegio Carlo Alberto, University of Hamburg, IRVAPP, LISER, SIEP, PAA, and Pop-days. We also thank Ainhoa Aparicio Fenoll, Larry Aber, Mauricio Avendano, Christopher Flinn, James Riccio, and Orla Doyle for helpful comments and suggestions. Special thanks are due to William Revello, Silvia Cordero, and Claudia Mandrile who helped us with the design and implementation of the intervention. The research is partly supported by Compagnia di San Paolo and Collegio Carlo Alberto. The randomized controlled trial object of this study was registered in the AEA RCT registry, AEARCTR-0001476.

†University of Turin, CHILD, Collegio Carlo Alberto, daniela.delboca@carloalberto.org.

$\ddagger$ University of Turin, CHILD, Collegio Carlo Alberto, chiaradaniela.pronzato@unito.it.

$\S$ University of Amsterdam, CHILD, Collegio Carlo Alberto, g.sorrenti@uva.nl. 


\section{Introduction}

Are conditional cash transfer (CCT) programs more effective than unconditional cash transfer (UCT) programs in reducing family poverty? In the last few decades, the majority of programs targeted to reduce poverty have taken the form of UCTs. Although these programs have helped to reduce family poverty in the short term, their long-term effects are mixed (Elango et al., 2015; Fernald, 2013; Gertler et al., 2014). Recent studies have shown that a more effective way to reduce the intergenerational persistence of poverty is to link economic support to "productive" behaviors such as investments in human and physical capital through CCTs (see Baird et al., 2011; Attanasio et al., 2012; Attanasio et al., 2015; Del Boca et al., 2016; Behrman et al., 2011; Behrman et al., 2012). ${ }^{1}$

CCT programs are based on the belief that poverty constraints often cause disadvantaged families to underinvest in human and physical capital. Families from disadvantaged backgrounds are not only limited by financial constraints that reduce their ability to save money or invest in human capital and health, they are also often uninformed about the returns of these investments (Cunha et al., 2013). Because low-income family members may be unaware of potential returns on their personal investment, CCT programs could become important to improving behavior and decision-making. Initially, CCT programs were more prevalent in developing countries, but recently, they have also been implemented in high-income countries where families' economic situations have worsened since the 2007 economic crisis. In these contexts, where the majority of families already use educational and health services, CCT programs are designed to provide more-accessible information and to incentivize a better use of resources (Miller et al., 2015).

This paper evaluates the impact of a CCT program on low-income household members' labor market outcomes and family economic conditions and well-being. We designed and implemented the CCT program in the Italian metropolitan area of Turin in 2016. The intervention targeted low-income families with a dependent child aged 0-6 and expanded an existing UCT program that has been running since 2008. Our CCT program conditions the income transfer on recipients' attending mentoring courses on job-seeking and reconciliation between work and family tasks.

\footnotetext{
${ }^{1}$ Fiszbein and Schady (2009) and Baird et al. (2014) provide extensive reviews on the impacts of CCT programs on schooling outcomes in low- and middle-income countries. CCT programs appear to have longer-term effects than UCTs (Baez and Camacho, 2011; Barham et al., 2017).
} 
Employment reduces a family's risk of poverty (OECD, 2009). Therefore, courses targeting individual labor market opportunities are among the most natural candidates to positively affect family economic conditions in both the short and the long runs. Accordingly, we introduced courses that provided information to potentially improve labor market opportunities, and we analyze the impact of the intervention on individuals' labor market outcomes and family well-being. ${ }^{2}$

We designed a randomized controlled trial (RCT) to compare the effectiveness of a conditional cash transfer program that requires recipients to attend mentoring courses versus a typical unconditional cash transfer program. We randomly assigned 1,500 families eligible for the cash transfer program to one of three experimental groups. A first group of families was entitled to receive an unconditional cash transfer (UCT), a second group of families received the same cash transfer conditional on attending mentoring courses (CCT), and a third control group (CG) was excluded from both the cash transfer and the courses. ${ }^{3}$ One year after admission to the program (or exclusion for the $\mathrm{CG}$ ), we administered to each family in the sample a comprehensive survey on household members' labor supply, well-being, and economic conditions.

The intervention displays two main effects. First, providing cash transfers along with mentoring courses (CCT) induces improvements in parental labor market outcomes such as employment or hours worked in the pre-interview week. ${ }^{4}$ We do not find any effect for households assigned to the UCT. On top of the labor supply effect, the CCT also seems effective in improving household economic conditions and well-being. Post-intervention, CCT families become more likely to collect some savings and report lower levels of financial dependency from people outside the household. A similar effect does not arise for the UCT group. Second, the treatment has different effects on mothers and fathers. The CCT treatment effect on labor market outcomes is almost exclusively driven by fathers. In the pre-interview week, fathers in the CCT group are more likely to work, i.e. +14 percent, and to work more than fathers in the UCT and in the CG groups. Wages seem unaffected by the intervention. There is no CCT

\footnotetext{
${ }^{2}$ The intervention offered four different courses. Given the extremely high unemployment rate experienced by families in the sample, (almost) all families were assigned to at least one course related to labor supply. We provide more details of the intervention and courses in Section 2.

${ }^{3}$ Our experiment left the total umber of cash transfer beneficiaries unaltered as compared to previous years.

${ }^{4}$ Due to the child-oriented eligibility criterion to receive the cash transfer, we refer to mothers and fathers of the youngest child in the household as units of observation in the analysis. For simplicity, we also label as fathers partners of mothers who are not the biological fathers of the youngest child in the household.
} 
treatment effect for mothers.

We investigate the possible mechanisms underlying the CCT treatment effect. CCT fathers invest more in activities that enhance labor market opportunities, e.g. enrollment in courses teaching informatics skills. Moreover, CCT families have better family networks than UCT or CG families. These networks might ease access to (better) labor market opportunities and consequently improve family well-being.

We contribute to the existing literature on cash transfers in three ways. First, our research evaluates a cash transfer program in a developed country. This setting contrasts with most studies that focus on developing countries. Cash transfer experiments in Europe are rare; the experiment helps illustrate their effectiveness in a context in which families face different sets of economic and information constraints. Second, we evaluate the impact of both a CCT and a UCT program in the same framework. Our design helps with the understanding of which approach might be more effective in reducing family poverty. Finally, we shed light on potential gender-specific heterogeneous treatment effects of cash transfer programs on labor market outcomes.

The remainder of the paper is organized as follows. Section 2 describes the intervention and the experimental design. Section 3 provides details on the data and the randomization protocol. Section 4 reports the baseline analysis. Section 5 discusses the mechanisms underlying the baseline results. Section 6 concludes.

\section{The Intervention}

The Experimental Design. Our intervention complements a preexisting income support program called Accoglienza Orientamento Supporto (AOS), which has been financed by Ufficio Pio in the metropolitan area of Turin since 2008. ${ }^{5}$ AOS represents a typical unconditional cash transfer program. Recipients are not required to engage in any desirable behavior to receive the cash transfer. AOS eligibility depends on two eligibility criteria: each family must have a family income below $€ 7,000$ as measured by the Indicator of the Equivalent Economic Situation (ISEE) and at least one dependent child under the age of six. ${ }^{6}$

\footnotetext{
${ }^{5}$ Turin is one of the largest metropolitan areas in Italy with about 2 million inhabitants. Ufficio Pio is a philanthropic institution based in Turin.

${ }^{6}$ ISEE measures family economic conditions in a standardized way and is calculated based on family composition, family members' earnings and other sources of income, and assets. The ISEE is issued through a certificate by the Italian National Pension System (INPS).
} 
Applications are accepted on a rolling basis, meaning families can apply to the program at any time of the year. Every two weeks, the Ufficio Pio collects the applications, determines whether eligibility criteria are met, and then establishes an income-based ranking of families eligible to receive the cash transfer. Applications from families who meet the admission criteria but who do not receive the cash transfer remain valid until December of the application year. If the family is not selected to receive the cash transfer by the end of the year, it is required to submit a new application for reconsideration.

The yearly cash transfer amounts to $€ 2,500-3,500 .^{7}$ This amount constitutes a sizable income shock. For the average family that received the cash transfer in 2016, the year of the intervention, the transfer covered up to 75 percent of the family's yearly labor income.

In 2015, the Ufficio Pio contacted us to request a proposal for redesigning AOS to improve the effectiveness of the program in combating poverty. In April 2016, we extended the AOS program by adding a conditional cash transfer component to the existing program. Since employment helps reduce poverty, the objective of our intervention was to tie cash transfers to household members' exposure to information regarding dimensions of family behavior with particular emphasis on labor supply. To receive the cash transfer, recipients of the conditional cash transfer had to attend two mentoring courses.

The original design of the intervention included four courses: job-seeking, reconciliation between work and family tasks, use of money, and parenting. As only three percent of applications were made by families with two working parents, all individuals in the conditional cash transfer group were assigned by an algorithm developed by the Ufficio Pio to the course on job-seeking or work-family conciliation. For this reason, we analyze the effectiveness of providing cash transfers conditional on exposure to mentoring courses covering topics related to individuals' labor market opportunities.

To evaluate whether providing mentoring courses and a cash transfer is more effective that simply providing monetary resources, we implemented an RCT based on the random assignment of 1,500 AOS-eligible families into three different experimental groups. ${ }^{8}$ The first group, consisting of 500 families, was entitled to receive the conditional cash transfer after attending two mentoring courses. One course covers labor market related topics. From now on, we label this group as the CCT group.

\footnotetext{
${ }^{7}$ The amount of the transfer varies according to the number of dependent children in the household.

${ }^{8}$ We use here illustrative groups sizes that are close to the ones obtained in the experimental setting.
} 
The second group, consisting of another 500 randomly selected families, received an unconditional cash transfer. Families within this group, the UCT group hereinafter, received the same amount of money as the CCT group, but they were uninformed about the existence of the mentoring courses offered to the CCT group, and therefore not required to attend. Finally, a third group of 500 families constituted the control group. This group, although eligible to receive the transfer, did not receive any cash transfer for the entire period covered by our analysis. We label this group as CG.

Figure 1: The Timeline of the Experiment

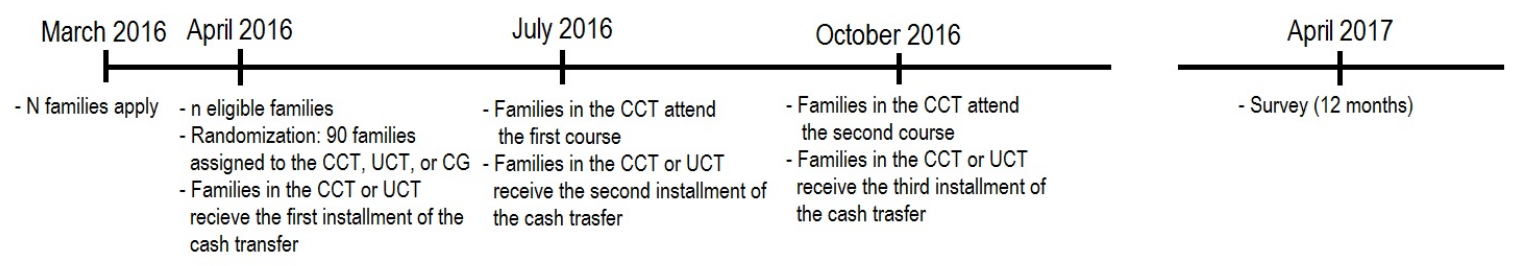

Notes: This figure shows the timeline of the experiment for representative families who applied in March 2016 and who were admitted to the program in April 2016. The same schedule, with a relative shift in months, applied to all families who applied for benefits from April through November 2016.

Figure 1 summarizes the timeline of the experiment. Applications were received and evaluated on a rolling basis. To obtain a population of around 1,500 families, our experiment covered those families admitted to the program during the nine-month period from April to December 2016. For simplicity, Figure 1 illustrates the case of families who applied in March 2016 for admission to the program that began in April 2016.

The process started when families applied to the program. Every two weeks the Ufficio Pio analyzed the $N$ applications received and selected the $n$ families $(n \leq$ $N)$ who were eligible to receive the cash transfer. The number of eligible families was usually close to 90 units every two weeks $(n \simeq 90)$. Once selected, we randomly assigned each of the $n$ families (randomization group) to one of the three experimental groups. Immediately afterward, families assigned to the CCT or the UCT group received the first installment of the cash transfer of $€ 500$. CCT families were also informed about the course attendance requirement and the specific courses each family was assigned to. Families had no power to choose or change the courses assigned by the Ufficio Pio.

Three months after program admission, CCT and UCT families received the second installment of the cash transfer, which ranged from $€ 1,000-1,500$. In order to receive the transfer, CCT families were required to attend the first assigned course. Payment 
was made upon verification by the Ufficio Pio that a family member attended 75 percent or more of the scheduled meetings. Six months after admission to the program, CCT and UCT families received the third installment, which ranged between $€ 1,000$ and 1,500 .

Twelve months after the assignment to experimental groups, we administered a final survey covering aspects related to household members' labor market outcomes, family well-being, and economic conditions.

The Courses: Assignment and Content. The take-up rate of courses was extremely high, with more than 85 percent of CCT families participating in each class and virtually all families fulfilling the requirement for the cash transfer. Each course consisted of five two-hour meetings. Only one family member was required to participate in the meetings. Translators helped the course instructors with individuals with limited Italian language proficiency.

The Ufficio Pio assigned the courses based on an algorithm that aimed to match specific family characteristics to appropriate courses. The assignment did not consider family preferences and families could neither choose nor change courses. As all of the families were characterized by extremely low levels of labor force participation, 93 percent of families were assigned to one of the two courses that emphasized the labor market.

The course on job-seeking aimed to enhance participants' labor market opportunities in two main ways. First, the course's objective was to provide participants with information on how to find suitable job opportunities. Second, the course aimed to foster participants' ability to recognize and evaluate their own skills and competencies. In one specific activity, the instructor described employers' typical recruitment procedures. Course participants learned about the functioning of work agencies, of websites to match job seekers' profiles with job advertisements, and how to search for internships or training support. In another activity, attention is focused on skills to enhance labor market opportunities, e.g. fluency in the Italian language or the ability to perform simple tasks with a computer. The activity provided information on specific external courses that participants could attend to acquire these skills. In another activity, participants learned how to prepare an effective profile or resume. The instructor provided each participant with practical guidance on how to prepare a resume.

The course on work-family reconciliation covered topics similar to the course on 
job-seeking but it also emphasized information and practices on how to reconcile work and family tasks. The course started with a summary of the job-seeking course content, e.g. job-search techniques and opportunities. Then, the course provided participants with basic information on services that had the potential to optimize the time devoted to family tasks. In one of the activities, participants received information on the supply of formal childcare (or similar services) in the municipality of Turin. Through this activity, participants learned about the availability and the very low cost of such services. ${ }^{9}$ Another proposed activity focused more on practical help for families. Each course participant obtained help preparing applications for childcare or other services that had the potential to ease work-family reconciliation. Finally, the course also covered topics related to the parent-child relationship and the possible benefits of a gender-neutral division of family tasks.

\section{Data and Randomization}

The Endline Survey. We administered the endline survey twelve months after families were assigned to the one of the three experimental groups. Each family was asked to fill out the same survey, which took approximately 40 minutes to complete. To prevent logistics problems, families completed the survey at home or at a public place of their choice. Students enrolled in the master's programs in economics and statistics of the University of Turin conducted the interviews. Translators assisted migrant families or other families with a limited Italian language proficiency. The mother of the youngest child in the household was interviewed. ${ }^{10}$ Families in the control group were offered a $€ 100$ food voucher as an incentive to fill out the questionnaire.

The survey consisted of two main sections. The first section collected general and demographics information for all household members. The main area of the second section of the survey covered household members' labor supply, job-seeking activities, and initiatives to enhance their professional profiles. This section of the survey also covered topics related to family members' social inclusion, use of services provided by the city, health status, and financial problems. Finally, mothers were asked about their children's enrollment in childcare or school, peer relationships, and health conditions. ${ }^{11}$

\footnotetext{
${ }^{9}$ For families eligible for the income support program, formal childcare would be free of charge.

${ }^{10}$ Single mothers constitute around 30 percent of our sample. We interviewed the mother of the youngest child in the household to ensure the same respondent across families.

${ }^{11}$ Refer to this link for the whole survey in Italian.
} 
Sample and Randomization Protocol. Table 1 shows CCT, UCT, and CG characteristics in the baseline (pre-participation, columns (1)-(3)) and in the final sample (post-participation, columns (4)-(6)). Table A.1 reports the baseline characteristics of the 1,481 families that were part of the initial sample.

Table 1 highlights two main facts. First, families in our sample were socio-economically disadvantaged. Half of the families had two unemployed parents, and only one percent of couples had both parents working. The disadvantaged economic background is reflected by family income (ISEE). The average ISEE in the sample is about $€ 900$, a level that corresponds to a family of two parents and two children, with a monthly rent of $€ 200$, and yearly labor earnings of $€ 4,700$. The extremely low employment rate of family members supports the idea of providing courses that emphasize labor market opportunities. $^{12}$

Second, the randomization protocol was correctly implemented. In the table, we report the average values of observable characteristics of the experimental groups as well as the statistical significance of the difference-in-means across the different groups. We test household composition, household members' demographics, education, employment status, and family income. Columns (1)-(3) test the initial (pre-participation) balancing. The 15 baseline characteristics measured at the time of application are balanced across groups, similar in absolute value, and any statistically significant difference arises across the three groups. For continuous variables, we show in Figure A.1 that the three experimental groups are balanced not only in terms of average values but also in their entire distribution. Indeed, the distribution of parents' age, age of the youngest child in the household, and family income are remarkably similar for all three experimental groups.

Balancing across experimental groups is preserved post-participation. In columns (4)-(6) we investigate possible selective attrition in the final sample (post-participation). The final sample consists of families for which information from the endline survey is available. In our specific framework, attrition might depend on families who: (i) are untraceable after the intervention so they do not take the endline survey, (ii) dropped out during the intervention, or (iii) refused to take the final survey. Columns (4)-(6) reveal that the initial random assignment is preserved post-participation. The response rate one year after admission to the program is about 72 percent and is similar across

\footnotetext{
${ }^{12}$ Our sample is characterized by a sizable fraction of about 75 percent of families with some migrant background.
} 
Table 1: Balancing Tests Across Treatment Groups Pre- and Post-Participation

\begin{tabular}{|c|c|c|c|c|c|c|}
\hline & \multicolumn{3}{|c|}{ Pre-Participation } & \multicolumn{3}{|c|}{ Post-Participation } \\
\hline & $\begin{array}{c}\mathrm{CCT} \\
(1)\end{array}$ & $\begin{array}{c}\mathrm{UCT} \\
(2)\end{array}$ & $\begin{array}{c}\text { CG } \\
(3) \\
\end{array}$ & $\begin{array}{c}\mathrm{CCT} \\
(4) \\
\end{array}$ & $\begin{array}{c}\text { UCT } \\
(5)\end{array}$ & $\begin{array}{c}\text { CG } \\
(6) \\
\end{array}$ \\
\hline In a couple & 0.70 & 0.67 & 0.68 & 0.70 & 0.68 & 0.68 \\
\hline Age mother & 34.9 & 35.0 & 35.1 & 35.4 & 34.9 & 35.4 \\
\hline Age father & 41.6 & 41.6 & 41.3 & 41.8 & 41.2 & 41.3 \\
\hline No Italian citizenship mother & 0.71 & 0.73 & 0.70 & 0.75 & 0.74 & 0.71 \\
\hline Number of children & 2.12 & 2.15 & 2.09 & 2.05 & 2.12 & 2.08 \\
\hline Age youngest child & 2.91 & 3.01 & 2.94 & 2.89 & 3.16 & 2.94 \\
\hline Secondary education mother & 0.40 & 0.39 & 0.39 & 0.41 & 0.39 & 0.38 \\
\hline Education in Italy mother & 0.35 & 0.38 & 0.33 & 0.36 & 0.38 & 0.33 \\
\hline Secondary education father & 0.42 & 0.42 & 0.39 & 0.41 & 0.41 & 0.39 \\
\hline Education in Italy father & 0.25 & 0.30 & 0.30 & $0.24^{*}$ & 0.30 & 0.31 \\
\hline In a couple, both work & 0.01 & 0.01 & 0.01 & 0.01 & 0.01 & 0.01 \\
\hline In a couple, one works & 0.48 & 0.45 & 0.46 & 0.48 & 0.48 & 0.46 \\
\hline In a couple, no one works & 0.51 & 0.54 & 0.53 & 0.51 & 0.51 & 0.54 \\
\hline Single parent works & 0.14 & 0.14 & 0.16 & 0.17 & 0.15 & 0.15 \\
\hline Family income (ISEE, in $€$ ) & 883 & 893 & 935 & 833 & 897 & 913 \\
\hline Observations & 503 & 500 & 478 & 350 & 370 & 351 \\
\hline
\end{tabular}

Notes: This table shows the average characteristics and the balancing tests across experimental groups. Columns (1)-(3) show the pre-participation analysis, namely right after the random assignment of families to groups. Columns (3)-(6) show the post-participation analysis, therefore only including those families who completed the endline survey and were part of the sample of the baseline analysis. CCT stands for the conditional cash transfer group, UCT stands for the unconditional cash transfer group, and CG stands for the control group. $*, * *, * * *$ indicate statistical significance for difference in average values with respect to the CG at the $10 \%, 5 \%$, and $1 \%$ levels, respectively. ${ }^{[*]},\left[{ }^{[*]},\left[{ }^{[* *]}\right.\right.$ indicate statistical significance for difference in average values between the CCT group and the UCT group at the $10 \%, 5 \%$, and $1 \%$ levels, respectively.

groups: 70 percent for the CCT group, 74 percent for the UCT group, and 73 percent for the CG. The analysis also suggests the absence of selective attrition. We perform 45 comparisons across experimental groups. Under random assignment, we would ex- 
pect to observe 0.5 comparisons statistically significant at the one percent level, 2.3 comparisons significant at the five percent level, and 4.5 comparisons significant at the ten percent level.

In our framework, only the difference between the CCT group and the CG in the share of fathers with education completed in Italy appears as statistically significant at the ten percent level. Figure A.2 shows that post-participation balancing across experimental groups holds also in terms of distribution of baseline characteristics. Any significant difference in the distribution of baseline parental age, age of the youngest child in the household, or family income is observed for the sample of families who completed the endline survey. Appendix A.2 provides a formal test for selective attrition that further confirms the post-participation balancing.

\section{Empirical Model and Baseline Results}

Equation 1 represents our reference empirical model:

$$
y_{i}=\beta_{0}+\beta_{1} C C T+\beta_{2} U C T+\mathbf{X}_{\mathbf{i}}^{\prime} \beta_{3}+\alpha_{i}+\epsilon_{i} \quad,
$$

where $i$ is the mother or the father of the youngest child in the household or, for familylevel outcomes, the family. $y_{i}$ is a set of outcomes covering labor market outcomes or measures for family economic conditions. Outcomes are measured through the endline survey administered twelve months after assignment to the experimental groups. $C C T$ is an indicator variable taking the value of one for families randomly assigned to the CCT group. UCT is an indicator variable taking the value of one for families randomly assigned to the UCT group. The CG represents the reference category. The vector $\mathbf{X}_{\mathbf{i}}$ contains a set of control variables for family income, number of household members under age 18, and indicator variables for mother's Italian citizenship and completed secondary education. $\alpha_{i}$ represents the randomization group fixed effects to take into account the rolling basis nature of the application process. $\epsilon_{i}$ represents the error term of the model. We are interested in the estimates of the parameters $\beta_{1}$ and $\beta_{2}$ that represent the $\mathrm{CCT}$ and the $\mathrm{UCT}$ treatment effect with respect to the $\mathrm{CG}$. 


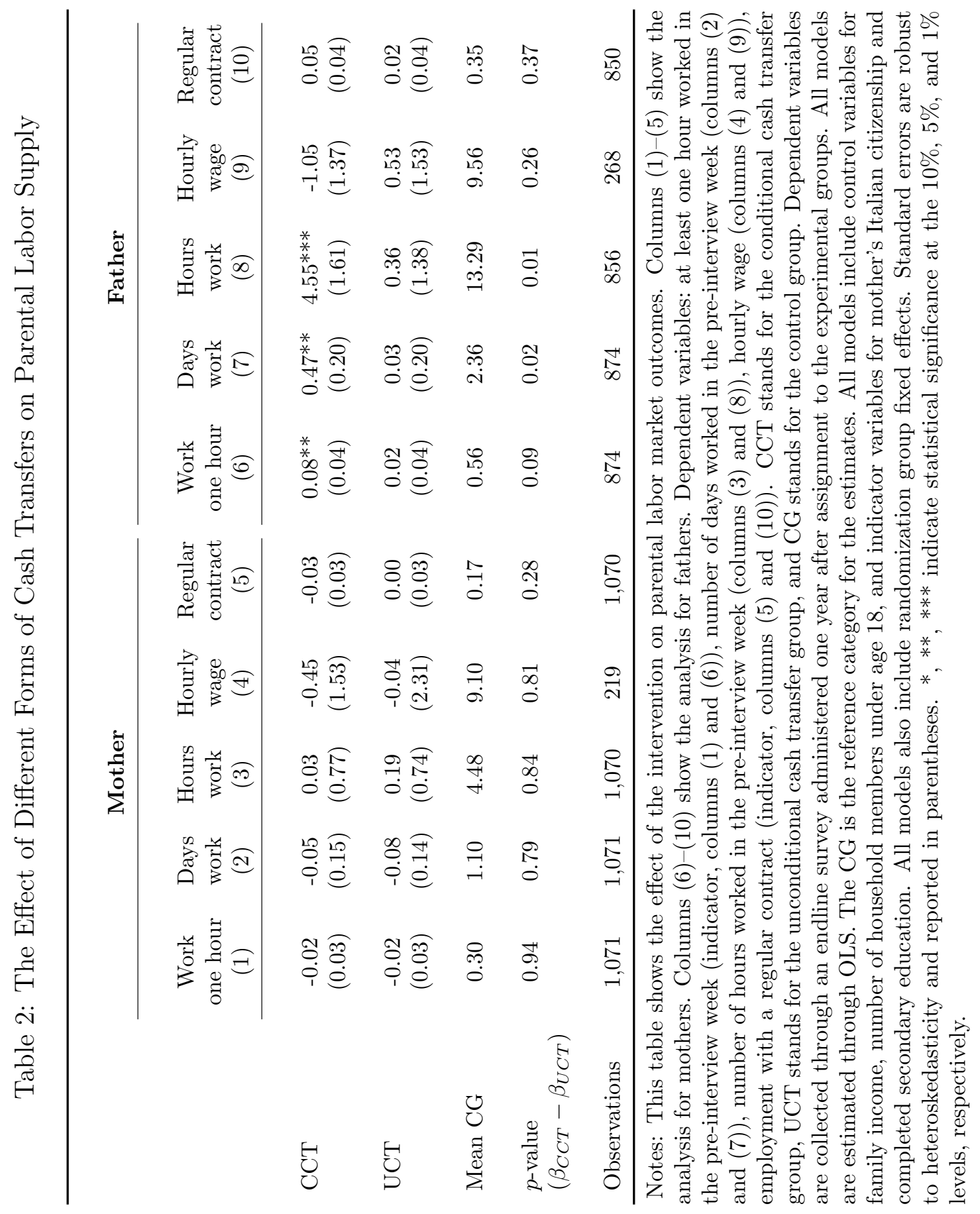


Household Labor Supply. Table 2 shows the treatment effect of the intervention on household members' labor supply. We focus on mothers in columns (1)-(5) and on fathers in columns (6)-(10). Our outcomes of interest are: at least one hour worked in the pre-interview week (indicator, columns (1) and (6)), number of days (columns (2) and (7)) and hours (columns (3) and (8)) worked in the pre-interview week, hourly wage (columns (4) and (9)), and being employed with a regular contract (indicator, columns (5) and (10)). We estimate OLS specifications with standard errors robust to heteroskedasticity. ${ }^{13}$

The analysis indicates no treatment effect on mothers' labor market outcomes. Column (1) highlights that the intervention does not increase, either for the CCT or for the UCT group, the probability of having worked in the pre-interview week. The analysis of days and hours worked (columns (2) and (3)) display the same pattern. The CCT and the UCT groups perform similarly to the CG. Maternal wage (column (4)) is also unaffected by the intervention as well as the probability of working with a regular contract (column (5)).

The intervention significantly affects fathers' labor market outcomes. One year after admission to the program, fathers in the CCT group become more likely to work than fathers in the CG. Column (6) highlights that the CCT treatment increases the probability of having worked by eight percentage points. This effect is economically relevant and it represents a 14 percent increase with respect to the CG mean. The treatment effect on father's labor supply is confirmed in terms of labor intensity: CCT fathers work, on average, half a day more $(+20$ percent, column $(7))$ or 4.5 additional hours $(+34$ percent, column (8)) than fathers in the CG. The increase in labor supply for CCT fathers is not mirrored by an improvement in labor market conditions. Column (9) points to the absence of the treatment effect on hourly wage with respect to the average hourly wage of $€ 9.50$ for the CG. Also, the probability of working with a regular work contract (column (10)) does not change in response to the intervention.

Fathers in the UCT seem unaffected by the pure cash transfer received. For all investigated outcomes, the labor market performance of fathers in the UCT group is similar to the performance of the CG. Moreover, as shown by the $p$-values for the test of equality between the CCT and the UCT treatment effect, the performance of UCT

\footnotetext{
${ }^{13}$ In Appendix A.2, we show that results are robust to clustering standard errors at the randomization group level. The existence of 16 clusters might raise concerns of bias induced by the relatively small number of clusters. For this reason, we present this analysis as a sensitivity check for baseline results.
} 
fathers is statistically worse than that of fathers in the CCT group. The difference in performance between the CCT and the UCT program suggests the possible importance of mentoring courses in shaping the intervention treatment effect. In Section 5 we investigate the possible mechanisms underlying this difference.

\section{Other Effects of the Intervention: Economic Conditions and Well-Being.}

Our intervention potentially affects household economic conditions and well-being through the cash transfer, the content of information covered by mentoring courses, and the labor supply effect previously documented. In Table 3, we analyze the intervention effect on family economic conditions and well-being by the accumulation of some savings during the last year, problems with the payment of utility bills in the last year, having an internet connection at home or on a cell phone, need for financial help from people outside the household in the last year, and worries about the future. All outcomes are expressed as indicator variables. We estimate linear probability models with standard errors robust to heteroskedasticity.

The intervention significantly improves CCT families' economic conditions and wellbeing. Indeed, CCT families tend to accumulate more savings (column (1)), they experience fewer problems with utility bills (column (2)), and they are more likely to have internet at home or on their phone (columns (3) and (4)). These effects translate into lower financial dependency on people outside the household (column (5)) and lower levels of worry about future (column (6)). To provide an idea of size effects, families in the CCT experience a seven percentage points increase in the probability of having saved some money and an eight percentage point decrease in arrears on utility bills. CCT families are eight percentage points less likely to be financially dependent on people outside the household.

The UCT intervention seems ineffective in improving family economic conditions and well-being. The (statistically) different performance between the CCT and the UCT families suggests that improvements in family economic conditions and well-being are likely driven by recipients' attending mentoring courses and by the intervention effect on labor supply.

Robustness. Appendix A.2 provides a robustness analysis for our baseline results. We replicate the baseline analysis of labor market outcomes by using inverse probability weighting to address potential residual concerns on selective attrition. We test 
the sensitivity of our results to the use of different standard errors. Finally, we test whether families selected to receive the cash transfer or mentoring courses misreport socially desirable behaviors. We select a subsample of outcomes characterized by social desirability and we show no treatment effect on these outcomes.

Table 3: The Intervention Effect on Family Economic Conditions and Well-Being

\begin{tabular}{|c|c|c|c|c|c|c|}
\hline & $\begin{array}{l}\text { Savings } \\
\text { (1) }\end{array}$ & $\begin{array}{c}\text { Arrears } \\
\text { Bills } \\
(2)\end{array}$ & $\begin{array}{c}\text { Internet } \\
\text { Home } \\
(3)\end{array}$ & $\begin{array}{c}\text { Internet } \\
\text { Phone } \\
(4)\end{array}$ & $\begin{array}{c}\text { Need } \\
\text { Financial } \\
\text { Help } \\
(5)\end{array}$ & $\begin{array}{c}\text { Worried } \\
\text { Future } \\
(6)\end{array}$ \\
\hline $\mathrm{CCT}$ & $\begin{array}{c}0.07 * * * \\
(0.02)\end{array}$ & $\begin{array}{c}-0.08 * * * \\
(0.03)\end{array}$ & $\begin{array}{c}0.10 * * * \\
(0.04)\end{array}$ & $\begin{array}{l}0.06^{*} \\
(0.03)\end{array}$ & $\begin{array}{c}-0.08^{* *} \\
(0.04)\end{array}$ & $\begin{array}{c}-0.07^{* *} \\
(0.03)\end{array}$ \\
\hline $\mathrm{UCT}$ & $\begin{array}{c}0.02 \\
(0.02)\end{array}$ & $\begin{array}{l}-0.05^{*} \\
(0.03)\end{array}$ & $\begin{array}{c}0.02 \\
(0.04)\end{array}$ & $\begin{array}{c}0.02 \\
(0.03)\end{array}$ & $\begin{array}{c}0.06 \\
(0.04)\end{array}$ & $\begin{array}{l}-0.03 \\
(0.03)\end{array}$ \\
\hline Mean CG & 0.08 & 0.89 & 0.33 & 0.72 & 0.57 & 0.79 \\
\hline $\begin{array}{l}p \text {-value } \\
\left(\beta_{C C T}-\beta_{U C T}\right)\end{array}$ & 0.09 & 0.33 & 0.03 & 0.28 & 0.00 & 0.34 \\
\hline Observations & 1,064 & 1,068 & 1,067 & 1,068 & 1,064 & 1,064 \\
\hline
\end{tabular}

Notes: This table shows the effect of the intervention on family economic conditions and well-being. Dependent variables: accumulation of some savings in the last year (column (1)), arrears on utility bills in the last year (column (2)), having internet at home (column (3)), having internet on the phone (column (4)), need for financial help from people outside the household in the last year (column (5)), being worried about the future (column (6)). All outcome variables are expressed as indicator variables. CCT stands for the conditional cash transfer group, UCT stands for the unconditional cash transfer group, and CG stands for the control group. Dependent variables are collected through an endline survey administered one year after assignment to the experimental groups. All models are estimated through OLS. The CG is the reference category for the estimates. All models include control variables for family income, number of household members under age 18, and indicator variables for mother's Italian citizenship and completed secondary education. All models also include randomization group fixed effects. Standard errors are robust to heteroskedasticity and reported in parentheses. *, $* *, * * *$ indicate statistical significance at the $10 \%, 5 \%$, and $1 \%$ levels, respectively. 


\section{Potential Mechanisms}

This section investigates two potential mechanisms through which mentoring courses might have fostered household members' labor supply and family economic conditions and well-being. On the one hand, mentoring courses provide individuals with a better knowledge of activities that foster labor market opportunities. On the other hand, attending courses with other individuals with similar socio-economic backgrounds might improve family networks. An improved family network is likely to increase knowledge and availability of labor market opportunities as well as financial and non-financial resource at a family's disposal.

Content of Courses and Job-Seeking Practices. Panel A of Table 4 displays the treatment effect of the intervention on important determinants of a successful jobseeking initiative. All outcome variables of this analysis are expressed as indicator variables and measured one year after assignment to the experimental groups. We estimate linear probability models with standard errors robust to heteroskedasticity.

We start with the analysis of mothers in columns (1)-(5). We observe marginal intervention effects on maternal investments. While assignment to the CCT group increase mothers' likelihood compared to the CG of having written a CV (column (1)) or of attending a computer skills course (column (3)), no effect is detected for attending Italian language courses (column (2)), attending professional courses (column (4)), or for job-search activities (column (5)). ${ }^{14}$ The pure income transfer received by UCT mothers does not affect any of the investigated outcomes. Traditional gender norms about child-rearing roles in the sample of families covered by the cash transfer program might underlie the limited intervention effects in both the CCT and UCT groups.

The analysis of fathers in columns (6)-(10) displays a sizable intervention effect. While the effect on the probability of having a CV (column (6)) is statistically insignificant, CCT fathers significantly increase investments in skills useful to compete in the labor market. For example, they become six percentage points more likely to take part in Italian language courses (column (7)), four percentage points more likely to attend courses teaching informatics skills (column (8)), and five percentage points more likely to attend professional courses (column (9)). The UCT group seems unaffected by the

\footnotetext{
${ }^{14}$ The courses analyzed in Table 4 are not the courses taken by CCT families as part of the intervention. The courses analyzed here are provided by external institutions and independently chosen and attended by individuals part of our sample. Professional courses teach skills necessary to perform specific jobs.
} 
Table 4: Potential Mechanisms

Panel A: Content of Courses and Job-Seeking

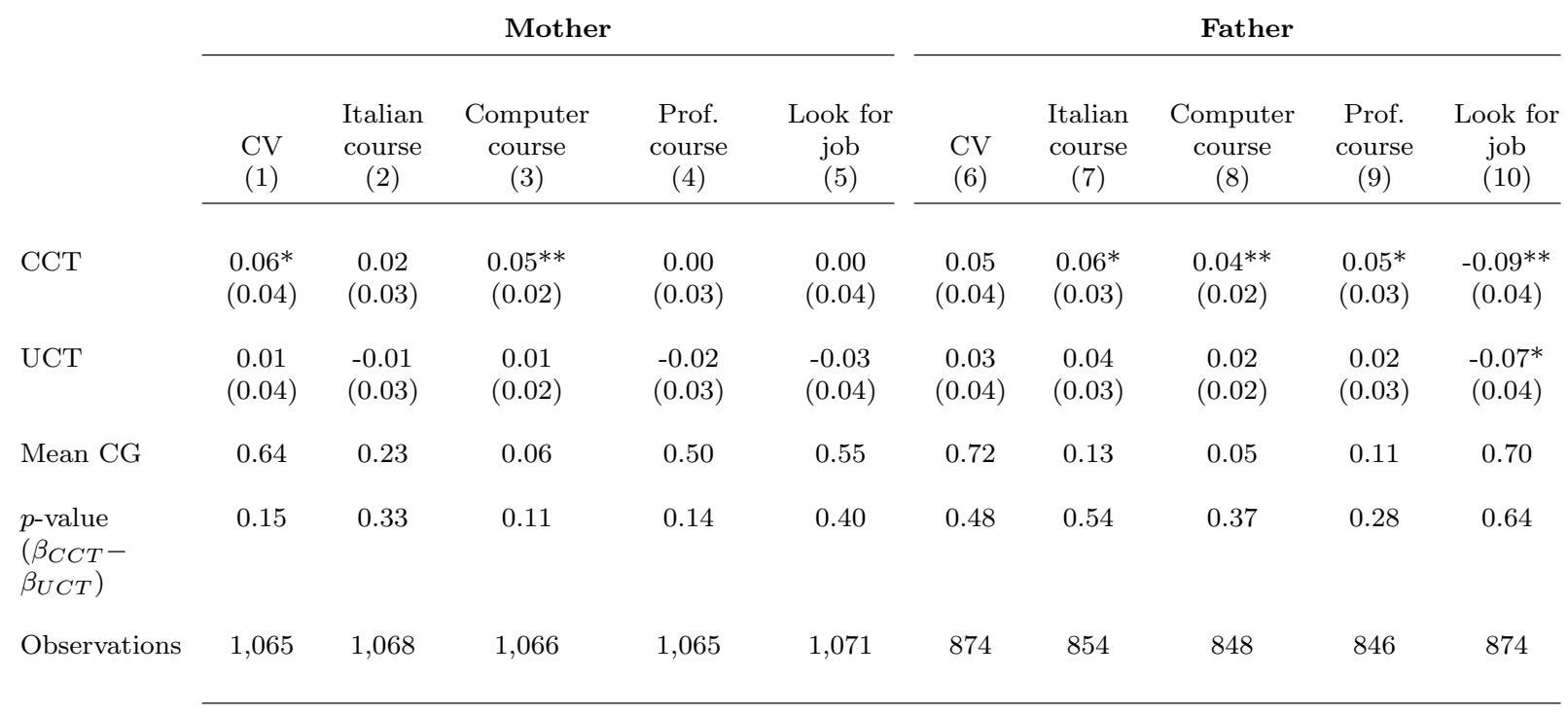

Panel B: Family Network

\begin{tabular}{|c|c|c|c|c|c|}
\hline & $\begin{array}{c}\text { Email } \\
(1)\end{array}$ & $\begin{array}{l}\text { Whats } \\
\text { App } \\
(2)\end{array}$ & $\begin{array}{c}\text { Facebook } \\
\text { (3) }\end{array}$ & $\begin{array}{c}\text { Nr. cont. } \\
\text { Facebook } \\
\quad(4)\end{array}$ & $\begin{array}{c}\text { Internet } \\
\text { for info } \\
\quad(5)\end{array}$ \\
\hline $\mathrm{CCT}$ & $\begin{array}{c}0.09^{* *} \\
(0.04)\end{array}$ & $\begin{array}{l}0.06^{*} \\
(0.03)\end{array}$ & $\begin{array}{c}0.09^{* *} \\
(0.04)\end{array}$ & $\begin{array}{c}21.14 \\
(21.99)\end{array}$ & $\begin{array}{c}0.11^{* * *} \\
(0.03)\end{array}$ \\
\hline $\mathrm{UCT}$ & $\begin{array}{c}0.02 \\
(0.04)\end{array}$ & $\begin{array}{c}0.05 \\
(0.03)\end{array}$ & $\begin{array}{c}0.05 \\
(0.04)\end{array}$ & $\begin{array}{c}7.95 \\
(16.06)\end{array}$ & $\begin{array}{l}0.06^{*} \\
(0.03)\end{array}$ \\
\hline Mean CG & 0.48 & 0.79 & 0.46 & 69.25 & 0.63 \\
\hline $\begin{array}{l}p \text {-value } \\
\left(\beta_{C C T}-\right. \\
\left.\beta_{U C T}\right)\end{array}$ & 0.07 & 0.70 & 0.38 & 0.53 & 0.18 \\
\hline Observations & 1,063 & 1,066 & 1,071 & 974 & 1,069 \\
\hline
\end{tabular}

Notes: This table shows the effect of the intervention on parental job-seeking practices (Panel A) and on family networks (Panel B). In Panel A, columns (1)-(5) show the analysis for mothers and columns (6)-(10) show the analysis for fathers. In Panel A, the dependent variables are: having a written CV (columns (1) and (6)), attending Italian language courses (columns (2) and (7)), attending courses teaching informatics and computer skills (columns (3) and (8)), attending professional courses (columns (4) and (9)), active job-search initiatives (columns (5) and (10)). All outcome variables are expressed as indicator variables. In Panel B, the dependent variables are: availability an email account (indicator, column (1)), use of WhatsApp (indicator, column (2)), use of Facebook (indicator, column (3)), number of Facebook contacts (column (4)), use of internet in the last year to find information (indicator, column (5)). In both panels, CCT stands for the conditional cash transfer group, UCT stands for the unconditional cash transfer group, and CG stands for the control group. Dependent variables are collected through an endline survey administered one year after assignment to the experimental groups. All models are estimated through OLS. The CG is the reference category for the estimates. All models include control variables for family income, number of household members under age 18, and indicator variables for mother's Italian citizenship and completed secondary education. All models also include randomization group fixed effects. Standard errors are robust to heteroskedasticity and reported in parentheses. *, $* *, * * *$ indicate statistical significance at the $10 \%, 5 \%$, and $1 \%$ levels, respectively. 
intervention. ${ }^{15}$ Interestingly, both CCT and UCT fathers appear less active than CG fathers in job-search initiatives (column (10)). Compared to the 70 percent baseline of the CG, this decrease is nine percentage points for the CCT fathers and seven percentage points for the UCT fathers. This effect might be a pure income effect induced by the cash transfer or, for the case of the CCT group, a labor supply effect. The treatment effect of the intervention on labor supply might indeed induce a reduction in the need to find a job.

Family Network. Families assigned to the CCT group attend mentoring courses with other families with similar socio-economic backgrounds. Attending group courses makes it easier to meet new people and improve the family network. Networks are particularly important for families targeted by the AOS income support program. As three-quarters of households eligible for AOS have some migrant background, linguistic and cultural barriers are often an obstacle for integration. Furthermore, improvements in family networks simplify access to labor market opportunities. ${ }^{16}$

Panel B of Table 4 investigates the intervention treatment effect on the quality and size of a family network by means of different outcomes measured one year after assignment to the experimental groups. Unless differently specified, all outcome variables are expressed as indicator variables. We estimate OLS specifications with standard errors robust to heteroskedasticity.

CCT families report better networks. In particular, they are significantly more likely than the CG to have an email account (column (1)), to use WhatsApp (column (2)) or Facebook (column (3)). The effect for the UCT group is statistically insignificant. The analysis of the number of Facebook contacts (column (4)) reveals that, in line with the effect on the probability of having an account, the CCT group has $21-$ imprecisely estimated - additional contacts compared to the CG average of 69 contacts. The increase for the UCT group amounts to eight contacts. The increase in the level of connections for treated families likely mirror an improved availability of information

\footnotetext{
${ }^{15}$ Admittedly, the $p$-values for the difference in the CCT versus UCT treatment effect is never statistically significant at the conventional levels. However, point estimates for the UCT are never statistically significant and are always smaller in size than those of the CCT. From a quantitative perspective, the CCT and the UCT treatment effects are usually (statistically) indistinguishable. From a qualitative perspective, the CCT usually overperforms the UCT.

${ }^{16}$ This is particularly true for the case of low-skilled jobs for which practices such as word of mouth or individual ties usually play a central role. About 40 percent of individuals in our sample work without a regular contract. For this type of worker, the importance of networks is even more salient as these jobs are not officially advertised.
} 
at the family level. Both the CCT and the UCT groups seem to use internet to search information more frequently (column (5)) than the CG, although the CCT effect is almost double the UCT effect. ${ }^{17}$

\section{Conclusions}

We analyze the effect on labor market outcomes and family economic conditions of a randomized controlled trial run in the Italian municipality of Turin targeting lowincome families with at least one dependent child. The intervention we designed allows us to compare a CCT versus a UCT program. The CCT program conditioned the receipt of the cash transfer on recipients' attending mentoring courses on job-seeking and work-family reconciliation. One year after random assignment to experimental groups, the CCT appears to be more effective than the cash transfer alone in (positively) affecting household members' labor market outcomes. The effect is visible and sizable for fathers in the sample and it is negligible for mothers. A positive CCT effect also arises on outcomes proxying family economic conditions such as the capacity to accumulate some savings or to pay utility bills on time.

The difference in performance between the CCT and the UCT programs suggests the importance of mentoring courses in shaping the treatment effects of the analysis. Our findings add to the growing evidence on the impact of CCTs versus UCTs and to the literature concerning multidimensional incentive programs. Future research should explore the long-run persistence of the treatment effects shown in this study.

\footnotetext{
${ }^{17}$ The CCT positive effect on family networks shown in Panel B of Table 4 seems to outperform i.e. has larger point estimates, the pure income effect observed for the UCT. However, the $p$-values for the difference in the treatment effect for the CCT versus the UCT is statistically significant only for the probability of having an email account.
} 


\section{References}

[1] Attanasio O., E. Battistin and A. Mesnard, 2012. "Food and Cash Transfers: Evidence from Colombia," Economic Journal 122(559), 92-124.

[2] Attanasio O., V. Oppedisano and M. Vera-Hernández, 2015. "Should Cash Transfers Be Conditional? Conditionality, Preventive Care, and Health Outcomes," American Economic Journal: Applied Economics 7(2), 35-52.

[3] Baez, J.E. and A. Camacho, 2011. "Assessing the Long-Term Effects of Conditional Cash Transfers on Human Capital: Evidence From Colombia," Policy Research working paper 5681. Washington, DC: World Bank.

[4] Baird, S., F.H.G. Ferreira, B. Özler and M. Woolcock, 2014. "Conditional, Unconditional and Everything in Between: A Systematic Review of the Effects of Cash Transfer Programmes on Schooling Outcomes," Journal of Development Effectiveness 6(1), 1-43.

[5] Baird S., C. McIntosh and B. Özler, 2011. "Cash or Condition? Evidence From a Cash Transfer Experiment," Quarterly Journal of Economics 126(4), 1709-1753.

[6] Barham T., K. Macours and J. Maluccio, 2017. "Are Conditional Cash Transfers Fulfilling Their Promise? Schooling, Learning, and Earnings After 10 Years," CEPR Discussion Papers 11937.

[7] Behrman J.R., J. Gallardo-García, S.W. Parker, P.E. Todd and V. Vélez-Grajales, 2012. "Are Conditional Cash Transfers Effective in Urban Areas? Evidence From Mexico," Education Economics $20=(3)$, 233-259.

[8] Behrman J.R., S.W. Parker and P.E. Todd, 2011. "Do Conditional Cash Transfers for Schooling Generate Lasting Benefits? A Five-Year Followup of PROGRESA/Oportunidades," Journal of Human Resources 46(1), 93-122.

[9] Cunha F., I. Elo and J. Culhane, 2013. "Eliciting Maternal Expectations About the Technology of Cognitive Skill Formation," NBER Working Paper 19144.

[10] Del Boca D., C. Flinn and M. Wiswall, 2016. "Transfers to Households with Children and Child Development," Economic Journal 126(596), F136-F183. 
[11] Elango S., J.L. García, J.J. Heckman and A. Hojman, 2015. "Early Childhood Education," NBER Working Paper 21766.

[12] Fernald L.C., 2013. "Promise, and Risks, of Conditional Cash Transfer Programmes," Lancet 382(9886), 7-9.

[13] Fiszbein A., and N. Schady, 2009. "Conditional Cash Transfers: Reducing Present and Future Poverty," Washington, DC: World Bank.

[14] Gertler P., J. Heckman, R. Pinto, A. Zanolini, C. Vermeersch, S. Walker, S.M. Chang and S. Grantham-McGregor, 2014. "Labor Market Returns to an Early Childhood Stimulation Intervention in Jamaica," Science 344(6187), 998-1001.

[15] Miller C., J. Riccio, N. Verma, S. Nuñez, N. Dechausay and E. Yang, 2015. "Testing a Conditional Cash Transfer Program in the U.S.: The Effects of the Family Rewards Program in New York City," IZA Journal of Labor Policy 4(11).

[16] OECD, 2009. "Is Work the Best Antidote to Poverty?," OECD Employment Outlook 2009 - Tackling the Jobs Crisis, 165-210. 


\section{Appendix: Additional Material}

\section{A.1 Additional Tables and Figures}

Table A.1: Summary Statistics - The Initial Sample

\begin{tabular}{|c|c|c|}
\hline & $\begin{array}{c}\text { Mean } \\
(1)\end{array}$ & $\begin{array}{c}\text { St. Dev. } \\
(2)\end{array}$ \\
\hline In a couple & 0.69 & 0.46 \\
\hline Age mother & 35.0 & 6.87 \\
\hline Age father & 41.5 & 7.78 \\
\hline No Italian citizenship mother & 0.71 & 0.45 \\
\hline Number of children & 2.12 & 1.11 \\
\hline Age youngest child & 2.96 & 2.51 \\
\hline Secondary education mother & 0.39 & 0.49 \\
\hline Education in Italy father & 0.35 & 0.48 \\
\hline Secondary education mother & 0.41 & 0.49 \\
\hline Education in Italy father & 0.28 & 0.45 \\
\hline In a couple, both work & 0.01 & 0.08 \\
\hline In a couple, one works & 0.47 & 0.50 \\
\hline In a couple, no one works & 0.53 & 0.50 \\
\hline Single parent works & 0.14 & 0.35 \\
\hline Family income (ISEE, in $€$ ) & 903 & 1,200 \\
\hline Observations & & 481 \\
\hline
\end{tabular}

Notes: This table shows the summary statistics for the initial sample of this study. 
Figure A.1: Additional Evidence on the Randomization Process - Pre-Participation
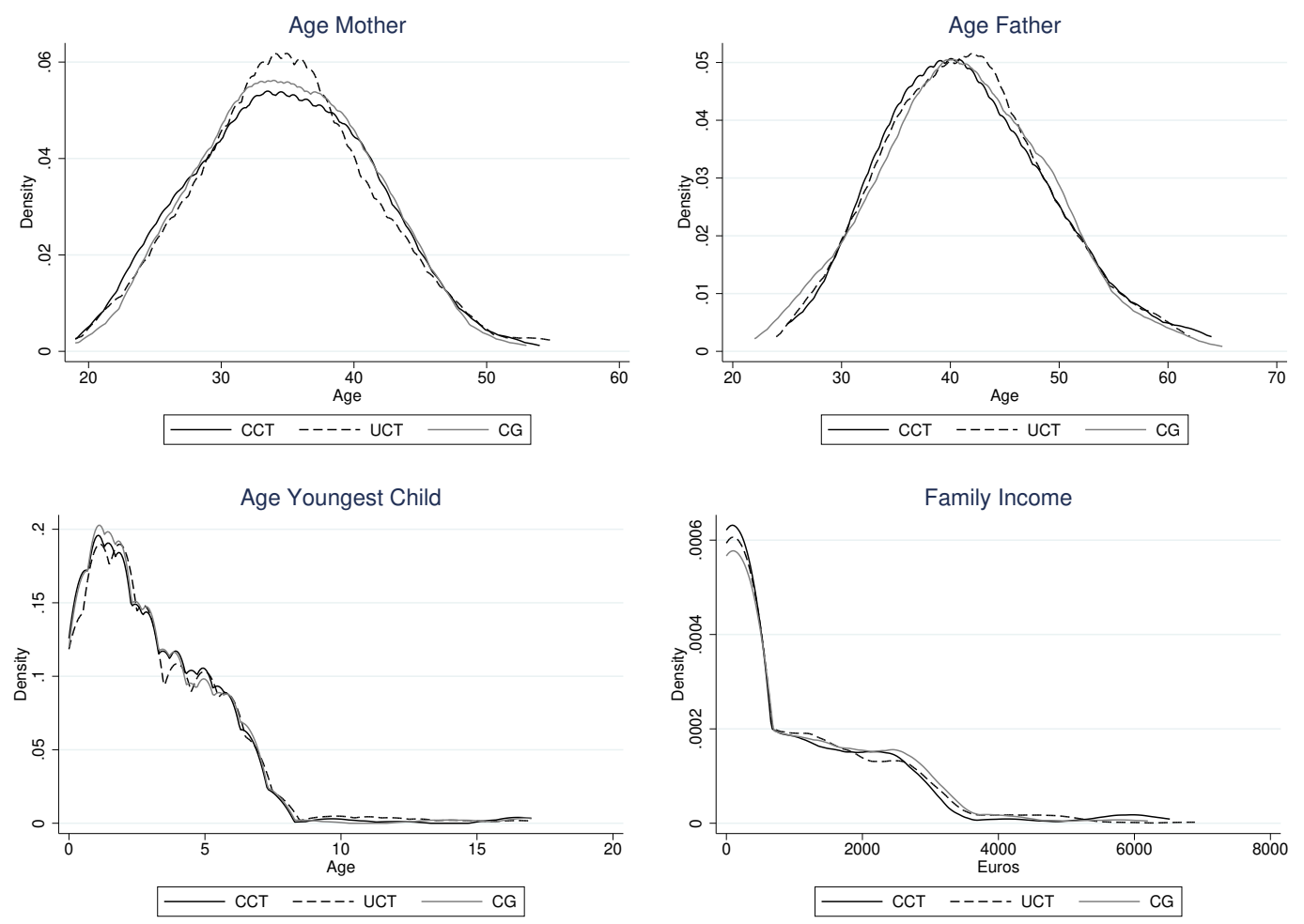

Notes: This figure shows the pre-participation distribution of a set of observable baseline (pretreatment) characteristics across experimental groups. The top-left panel shows the distribution of mothers' age. The top-right panel shows the distribution of fathers' age. The bottom-left panel shows the distribution of age of youngest child in the household. The bottom-right panel shows the distribution of family income (ISEE, in $€$ ). All panels show on the y-axis the univariate Kernel density estimations. For each panel, the black solid line represents the distribution for the CCT, the black dashed line represents the distribution for the UCT, and the gray solid line represents the distribution for the CG. CCT stands for the conditional cash transfer group, UCT stands for the unconditional cash transfer group, and CG stands for the control group. 
Figure A.2: Additional Evidence on the Randomization Process - Post-Participation
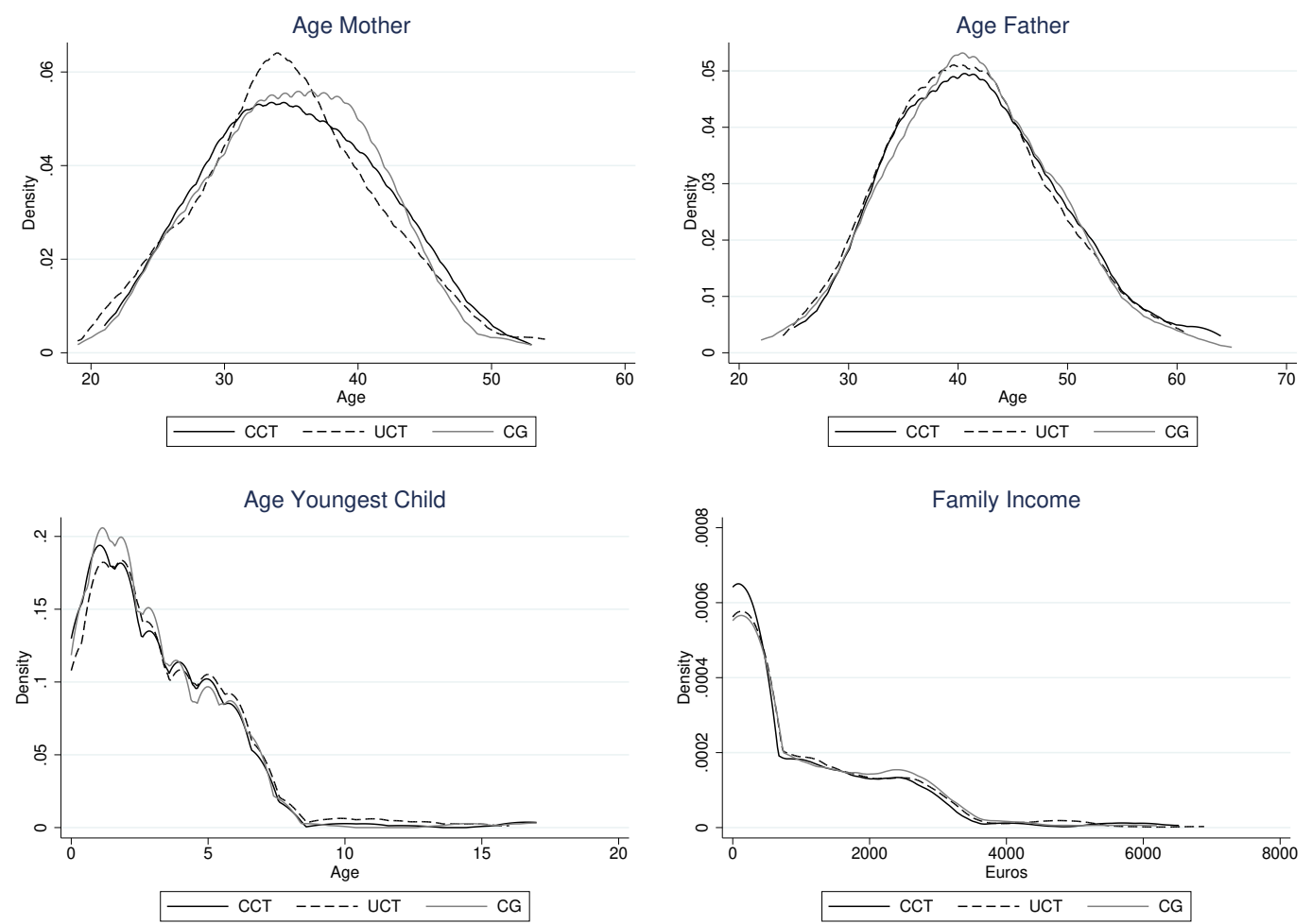

Notes: This figure shows the post-participation distribution of a set of observable baseline (pretreatment) characteristics across experimental groups. The post-participation sample only includes those families completing the endline survey and part of the baseline analysis. The top-left panel shows the distribution of mothers' age. The top-right panel shows the distribution of fathers' age. The bottom-left panel shows the distribution of age of youngest child in the household. The bottomright panel shows the distribution of family income (ISEE, in $€$ ). All panels show on the y-axis the univariate Kernel density estimations. For each panel, the black solid line represents the distribution for the CCT, the black dashed line represents the distribution for the UCT, and the gray solid line represents the distribution for the CG. CCT stands for the conditional cash transfer group, UCT stands for the unconditional cash transfer group, and CG stands for the control group. 


\section{A.2 Robustness Analysis}

In this appendix, we provide a set of robustness tests for our baseline results. We start with the analysis of selective attrition. Second, we test the robustness of our findings to a different choice of standard errors. Finally, we study positive response bias to check whether families selected to receive the cash transfer or mentoring courses misreport socially desirable behaviors.

Selective Attrition. To preserve the validity of the random assignment, we would need the assignment to one specific experimental group not to affect the probability that a family completes the endline survey. We provide a dual test for selective attrition. First, in Table 1 in the text (complemented by Figure A.2) we compare baseline characteristics across the three experimental groups of families that were part of the final sample. Second, we implement a formal regression analysis for selective attrition. Specifically, we estimate whether the assignment to a specific experimental group determines the probability of observing that a family completes the endline survey. Then we re-estimate our baseline models with inverse probability weighting to take into account possible selective attrition.

In Table A.2 we analyze the possible effect of a family's assignment to one specific experimental group on the probability of observing attrition. Under the assumption of absence of selective attrition, we should find that the (random) assignment to a specific experimental group does not predict attrition. We estimate four different specifications to test selective attrition. The dependent variable is an indicator that takes the value of one if the family is not part of the final sample. In columns (1) and (2), we estimate a logistic regression model. The specification in column (1) does not contain control variables. In column (2) we replicate the same model including

baseline control variables measured at the time of application to the program. In columns (3) and (4), we perform the OLS estimates without and with control variables, respectively. The vector of control variables in columns (2) and (4) includes all the baseline characteristics that are available for all families in the sample, namely family income, being in a couple, the number of children in the household, the age of the youngest child in the household, mother's citizenship, education, and working status at the time of application to the program. As about one-third of mothers are single; we do not include father's characteristics as control variables.

The analysis in Table A.2 suggests that neither the assignment to the CCT group, 
Table A.2: Testing for Selective Attrition

\begin{tabular}{lcccc}
\hline & \multicolumn{4}{c}{ Indicator for Attrition } \\
\cline { 2 - 5 } & $\begin{array}{c}\text { Logit } \\
(1)\end{array}$ & $\begin{array}{c}\text { Logit } \\
(2)\end{array}$ & $\begin{array}{c}\text { OLS } \\
(3)\end{array}$ & $\begin{array}{c}\text { OLS } \\
(4)\end{array}$ \\
\cline { 2 - 5 } & & & & \\
CCT & 0.19 & 0.16 & 0.04 & 0.03 \\
& $(0.14)$ & $(0.14)$ & $(0.03)$ & $(0.03)$ \\
UCT & -0.03 & -0.03 & -0.01 & -0.01 \\
& $(0.15)$ & $(0.15)$ & $(0.03)$ & $(0.03)$ \\
Controls & No & Yes & No & Yes \\
Observations & 1,481 & 1,455 & 1,481 & 1,455 \\
\hline
\end{tabular}

Notes: This table shows the estimates for the effect on attrition of the assignment to a specific treatment condition. Dependent variable: indicator for attrition. Columns (1) and (2) report the estimates of a logistic regression model. Columns (3) and (4) report the OLS estimates. Models in columns (1) and (3) do not include control variables. Models in columns (2) and (4) include baseline control variables for family income, two-parent household, number of household members under age 18, the age of the youngest child in the household, mother's Italian citizenship, mother's education, and mother's working status. CCT stands for the conditional cash transfer group, UCT stands for the unconditional cash transfer group, and CG stands for the control group. The CG is the reference category for the estimates. Standard errors are robust to heteroskedasticity and reported in parentheses. *, **,*** indicate statistical significance at the $10 \%, 5 \%$, and $1 \%$ levels, respectively.

nor the assignment to the UCT group explains statistically significant changes in the probability of taking part in the final survey. If anything, the CCT group seems marginally more likely ( +3 percentage points) than the CG not to complete the survey. This effect is statistically insignificant. 


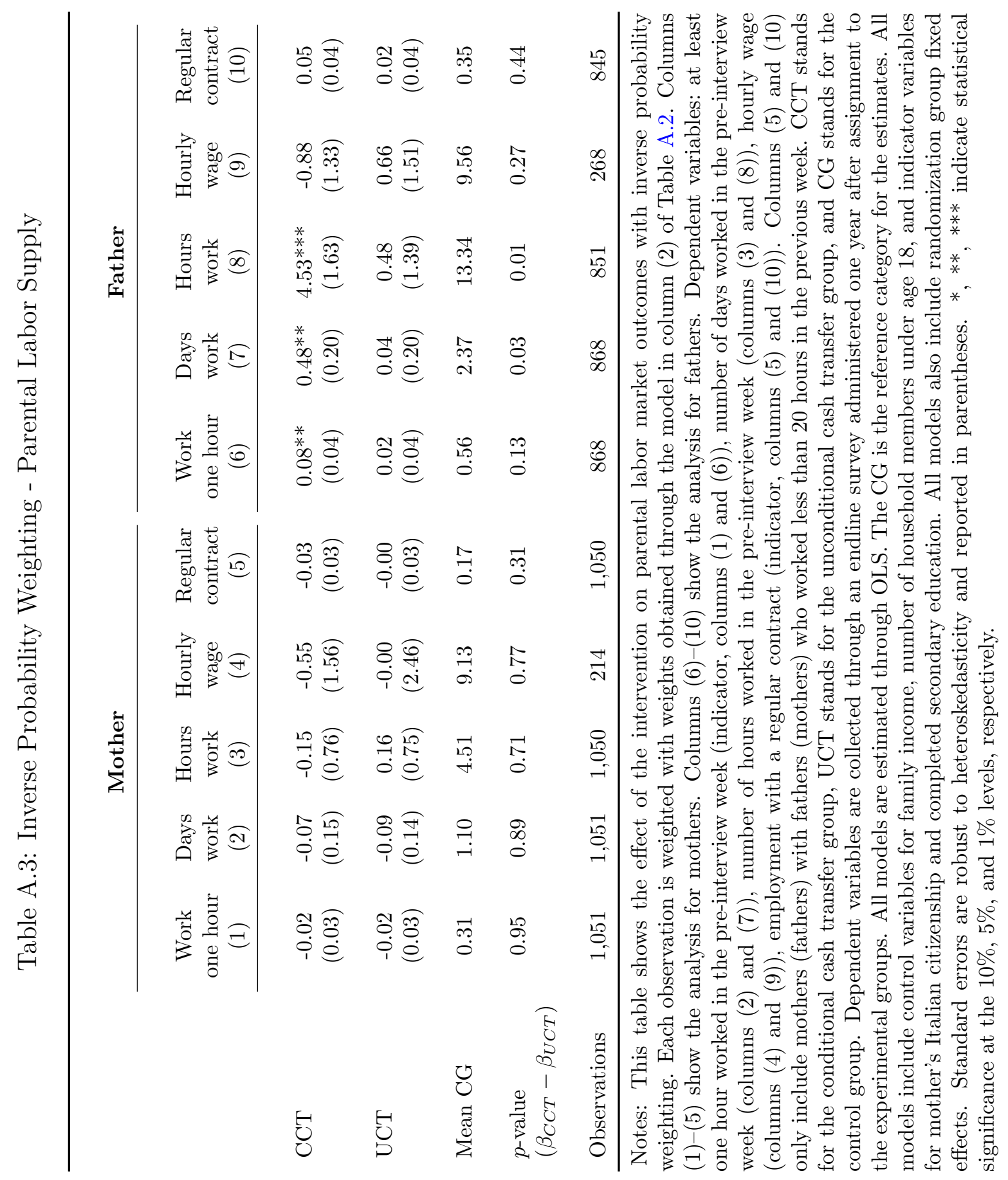


Table A.4: Inverse Probability Weighting - Economic Conditions and Well-Being

\begin{tabular}{|c|c|c|c|c|c|c|}
\hline & $\begin{array}{l}\text { Savings } \\
\quad(1)\end{array}$ & $\begin{array}{c}\text { Arrears } \\
\text { Bills } \\
(2)\end{array}$ & $\begin{array}{c}\text { Internet } \\
\text { Home } \\
(3)\end{array}$ & $\begin{array}{c}\text { Internet } \\
\text { Phone } \\
(4)\end{array}$ & $\begin{array}{c}\text { Need } \\
\text { Financial } \\
\text { Help } \\
(5)\end{array}$ & $\begin{array}{c}\text { Worried } \\
\text { Future } \\
\text { (6) }\end{array}$ \\
\hline $\mathrm{CCT}$ & $\begin{array}{c}0.07 * * * \\
(0.02)\end{array}$ & $\begin{array}{c}-0.08 * * * \\
(0.03)\end{array}$ & $\begin{array}{c}0.10^{* * *} \\
(0.04)\end{array}$ & $\begin{array}{c}0.05 \\
(0.03)\end{array}$ & $\begin{array}{c}-0.08^{* *} \\
(0.04)\end{array}$ & $\begin{array}{l}-0.06^{*} \\
(0.03)\end{array}$ \\
\hline $\mathrm{UCT}$ & $\begin{array}{c}0.02 \\
(0.02)\end{array}$ & $\begin{array}{r}-0.05^{*} \\
(0.03)\end{array}$ & $\begin{array}{c}0.02 \\
(0.04)\end{array}$ & $\begin{array}{c}0.02 \\
(0.03)\end{array}$ & $\begin{array}{c}0.06 \\
(0.04)\end{array}$ & $\begin{array}{l}-0.03 \\
(0.03)\end{array}$ \\
\hline Mean CG & 0.08 & 0.89 & 0.33 & 0.72 & 0.57 & 0.79 \\
\hline $\begin{array}{l}p \text {-value } \\
\left(\beta_{C C T}-\beta_{U C T}\right)\end{array}$ & 0.08 & 0.32 & 0.03 & 0.34 & 0.00 & 0.45 \\
\hline Observations & 1,045 & 1,049 & 1,048 & 1,049 & 1,045 & 1,045 \\
\hline
\end{tabular}

Notes: This table shows the effect of the intervention on family economic conditions and wellbeing with inverse probability weighting. Each observation is weighted with weights obtained through the model in column (2) of Table A.2. Dependent variables: accumulation of some savings in the last year (column (1)), arrears on utility bills in the last year (column (2)), having internet at home (column (3)), having internet on the phone (column (4)), need for financial help from people outside the household in the last year (column (5)), being worried about the future (column (6)). All outcome variables are expressed as indicator variables. CCT stands for the conditional cash transfer group, UCT stands for the unconditional cash transfer group, and CG stands for the control group. Dependent variables are collected through an endline survey administered one year after assignment to the experimental groups. All models are estimated through OLS. The CG is the reference category for the estimates. All models include control variables for family income, number of household members under age 18, and indicator variables for mother's Italian citizenship and completed secondary education. All models also include randomization group fixed effects. Standard errors are robust to heteroskedasticity and reported in parentheses. *,**,*** indicate statistical significance at the $10 \%, 5 \%$, and $1 \%$ levels, respectively.

To further test for selective attrition, we replicate the baseline results of Tables 2 and 3 in the text through inverse probability weighting. For our initial sample, we predict the individual probability of being part of the final sample based on the model in column (2) of Table A.2. Then, we weight each observation in the sample by the inverse of the predicted probability of being observed in the final sample. Tables A.3 and A.4 report the analysis and highlight that any significant difference is observed 
when baseline estimates are compared with estimates obtained through inverse probability weighting.

Alternative Standard Errors. In this section we test the robustness of the results to the use of alternative standard errors. In the paper, we use heteroskedastic standard errors. We take into account the rolling basis nature of the application process to the cash transfer program we analyze. The rolling basis application process might indeed induce error correlation between families applying at the same time of the year and therefore, into part of the same randomization group. To test this possibility, we reestimate the baseline analysis of household members' labor supply in Table 2 of the paper by using standard errors clustered at the randomization group level. There are 16 randomization groups in our sample. The analysis is reported in Table A.5 and shows that results are unaffected by the use of clustered at the randomization group level standard errors. 


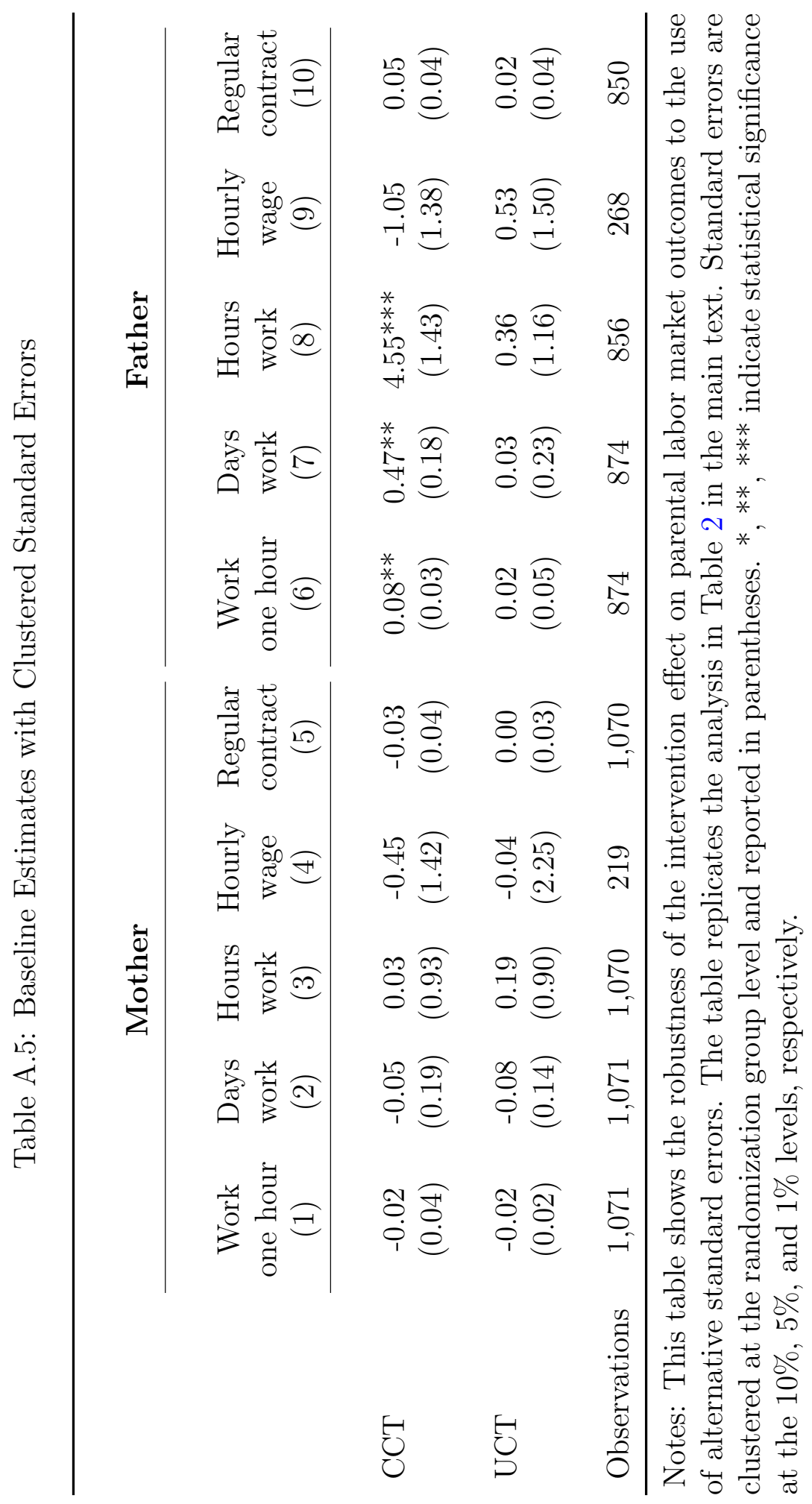


Social Desirability and Positive Response Bias. Families selected to receive the cash transfer or mentoring courses may be inclined to misreport socially desirable behaviors. This threat might be particularly relevant for individuals assigned to the CCT group who attended courses that mentored them about good practices to succeed in the labor market or to reconcile work and family duties.

We run two sets of tests for positive response bias. First, we test a set of outcomes not covered by mentoring courses. These outcomes help with the understanding of whether individuals treated with the cash transfer tend to overreport virtuous behaviors compared to the CG. Second, we exploit a set of questions in our endline survey on highly desirable behaviors that were related and particularly highlighted by the material covered by courses. The CCT group might be particularly inclined to overreport these behaviors as a result of courses' attendance. For both sets of tests, in the presence of positive response bias, we might expect to find positive treatment effects of the intervention for all (or some) outcomes with socially desirable connotations. On the contrary, the absence of the treatment effect would suggest that treated families in the CCT and the UCT groups do not tend to overreport behavior if the behavior can be considered as socially desirable. Table A.6 shows the analysis.

Columns (1)-(3) of Table A.6 investigate the treatment effect of the intervention on behaviors not directly covered by mentoring courses. We analyze participation at municipal events in the last year (column (1)), child's friends visits at home in the preinterview month (column (2)), and child visits at friends' homes in the pre-interview month (column (3)). All outcomes are expressed as indicator variables. We estimate linear probability models with standard errors robust to heteroskedasticity. All the outcomes investigated in columns (1)-(3) may be defined as highly socially desirable: they relate to family involvement in the surrounding social environment and some of these activities, e.g. meeting friends, are potential ways for mothers to reconcile work and family duties. However, these topics were not directly covered by mentoring courses. None of the investigated outcomes is significantly affected by the intervention. The CCT and the UCT groups perform similarly and their performance aligns with the CG. The absence of treatment effect suggests that survey respondents are unlikely to be biased in their responses by the degree of social desirability of behaviors not directly covered by mentoring courses. 


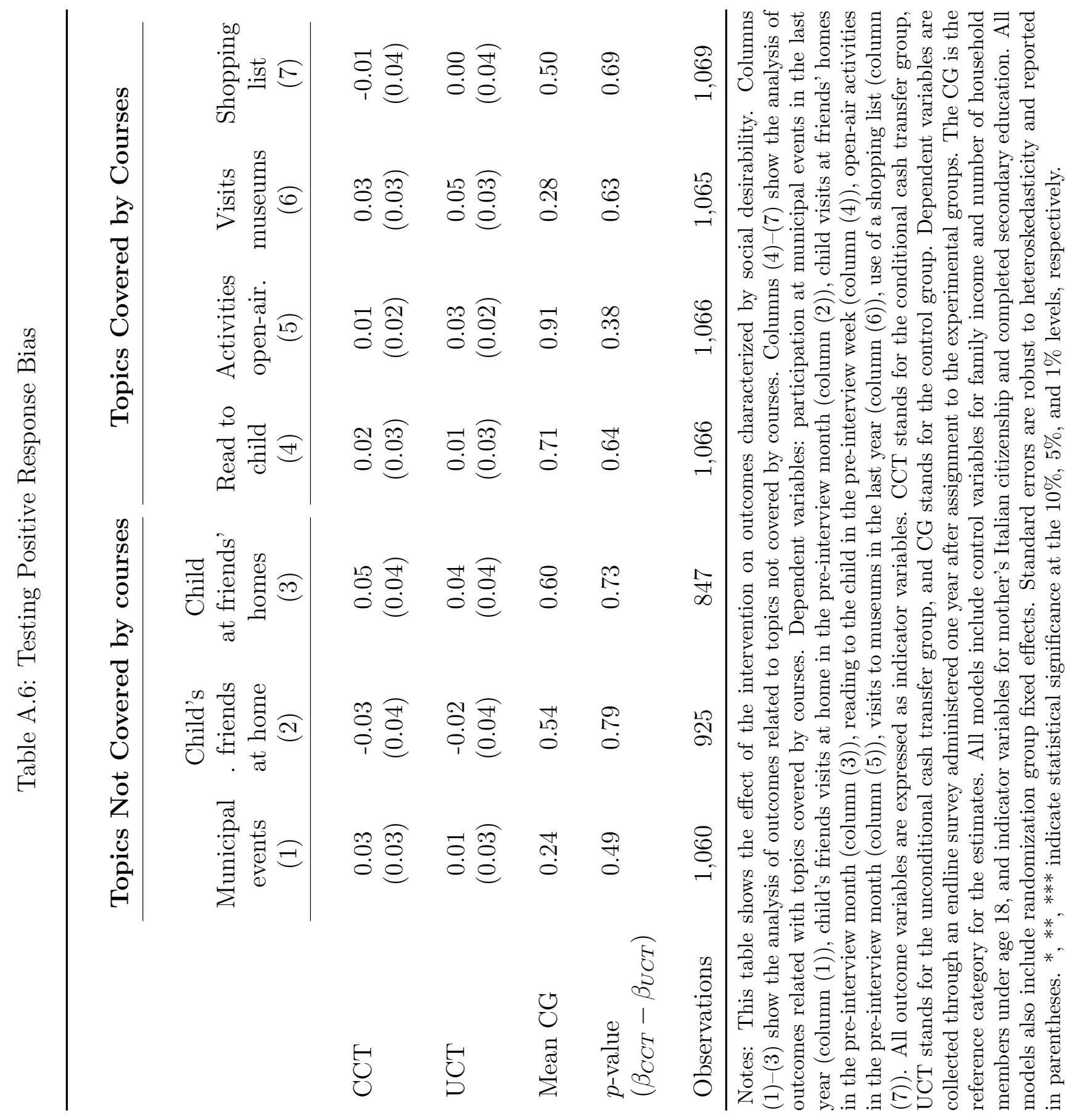


Columns (4)-(7) of Table A.6 focus the analysis on desirable outcomes related to topics directly covered by mentoring courses attended by CCT families. The dependent variables are reading to the child in the pre-interview week (column (4)), open-air activities in the pre-interview month (column (5)), visits to museums in the last year (column (6)), and use of a shopping list (column (7)). These behaviors might be classified as socially desirable and, at the same time, they were highlighted during mentoring courses as important tools to improve the parent-child relationship, especially for working parents, or family economic and financial conditions. None of the outcomes is affected by the intervention. In particular, the CCT group, which was exposed to mentoring courses emphasizing the importance of these behaviors, does not report any increase with respect to the CG. This analysis reassures that the CCT group seems unlikely to overreport socially desirable behavior just because these behaviors were covered by the mentoring courses they had to attend. 